\title{
Una mirada crítica a las repercusiones de la televisión en la educación
}

\author{
Salvador Peiró i Grègori
}

Universidad de Alicante. Alicante, España. Email: salvador.peiro@ua.es

\section{Gladys Merma Molina}

Universidad de Alicante. Alicante, España. Email: gladys.merma@ua.es

\begin{abstract}
Resumen: Esta investigación está contextualizada en torno a la influencia que ejercen las tecnologías de la información y de la comunicación, en la educación informal. En concreto, nuestro objetivo es reflexionar sobre la televisión. Para ello, partimos de un análisis teórico, que nos permite entender cómo ha cambiado el significado de algunos conceptos claves, como educación y comunicación, en la postmodernidad globalizada. Con los datos derivados de diversas investigaciones, determinamos cuál es el impacto de la televisión en los niños y adolescentes, valoramos sus efectos educacionales y su influencia en diversos aspectos de la persona, fundamentalmente en su conducta. No obstante los resultados negativos que reflejan estos trabajos, debemos tener en cuenta los efectos positivos de la televisión, que resultan menos subrayados y que pueden ser más abundantes si son cabalmente planeados, desde el ámbito educativo. Finalmente, esta investigación nos permite constatar que hay una asignatura pendiente: dar un nuevo impulso a nuestro desarrollo humano y ético, con ayuda de las tecnologías. Partiendo de la importancia de la "escuela paralela", creemos que es posible elaborar un nuevo modelo educativo integral, que responda a los retos que nos plantea la sociedad moderna.

Palabras clave: tecnologías de la información y de la comunicación, televisión, comunicación, educación.
\end{abstract}

\section{A critical view to the impact of television on education}

\begin{abstract}
This research is contextualized around the influence that the technologies' of information and communication have on informal education. Specifically, our aim is to analyze television. To do this, we start from a theoretical analysis that allows us to understand how the meaning of some key concepts such as education and communication in globalized postmodernity have change. With data derived from some researches, we determine the impact of television on children and adolescents, and argue about their educational effects and their influence on various aspects of a person, primarily in its behavior. Despite the negative results that these works show, we must all the same consider the positive effects of television, which are less emphasized and which may be more abundant, if they would be thoroughly planned from the education field. Finally, this research enables us to see that there is a pending issue: to give new impetus to our human development and ethics, with the help of technology. Based on the importance of "parallel school", we believe it is possible to develop a new comprehensive educational model that would respond to the challenges we face in modern society.
\end{abstract}

Key words: information and communication technologies, television, communication, education. 


\section{Um olhar crítico sobre o impacto da televisão na educação}

Resumo: Esta pesquisa é contextualizada em torno da influência das tecnologias da informação e comunicação na educação informal. Especificamente, nosso objetivo é refletir sobre a televisão. Para isso, partimos de uma análise teórica que nos permite compreender como ele mudou o significado de alguns conceitos-chave como educação e comunicação na pós-modernidade global. Com os dados de vários estudos, determinamos qual é o impacto da televisão sobre crianças e adolescentes eo valor dos seus efeitos educacionais e sua influência sobre vários aspectos da pessoa, principalmente em seu comportamento. Apesar dos resultados negativos refletida por essas obras, devemos considerar os efeitos positivos da televisão, que são menos destaque e pode ser mais abundante se totalmente planejada desde o campo da educação. Finalmente, esta pesquisa permite verificar que existe um longo atraso para dar um novo impulso ao nosso desenvolvimento humano e ético, com a ajuda da tecnologia. Com base na importância da "escola paralela”, acreditamos que é possível desenvolver um modelo abrangente de que responde aos desafios colocados pela sociedade moderna.

Palavras-chave: tecnologias da informação e comunicação, televisão, comunicação, educação.

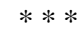

\section{Delimitación de la educación y de la comunicación}

Esteve, (1983: 71) plantea la red de términos de educación, la educación estricta como culmen e integración de procesos como instrucción y formación, cuando el educando llega a efectuar el ejercicio libre de su voluntad. Esto presupone un dominio suficiente de la capacidad de llevar a cabo raciocinios y juicios de valor, además de poseer ciertas virtudes humanas. Asimismo, un aspecto negativo considerado por el mismo autor es el de manipulación, pues impide la formación de la conciencia, que es previa a la toma de decisiones y ejecución libre.

En el lenguaje español o en el inglés, el vocablo manipulación tiene un sentido peyorativo: en vez de aplicar la habilidad en el trato con el otro con intención de bien hacer, pasa a ser signo de la inclinación a ver en los demás simplemente cosas a dominar para los propios intereses. Para conseguirlo, no se repara ante el uso, generalmente subrepticio, de métodos que atacan la dignidad ajena en cuanto pretenden despojar al otro de su deliberación personal, que busca ser sustituida por el fin que el manipulador desea (Ibáñez-Martín y Mellado, 1974).

Como ver la televisión, en cualquiera que sean sus formas, al igual que el educar, se materializan en forma de comunicación, debemos sintetizar el sentido humano que debe tener esta relación dinámica entre sujetos. Desde la antropología (Choza, 1990), sabemos que hay tres niveles posibles de efectuar comunicación. Una es la comunicación biológica: no transforma los contenidos en otro tipo de seres; lo que está fuera, siendo diferente al sujeto, incluso no vivo, al pasar dentro del individuo, se vivifica tal 
como es el sujeto viviente que lo asume: este tipo de comunicación, por supuesto no es educativa, aunque es medio para que se dé. La segunda manera es la comunicación mediada por el conocimiento: la diferencia con el nivel anterior estriba en que el centro de gravedad pasa de la función biológica a la intelectiva; mas ésta no es propiamente humana, es de tipo natural, de especie, instintiva, compartida por todo viviente; no es un saber de sentido, sino de dominio por el mensaje genético; esto significa un enterarse de modo inconsciente o paraconsciente. Está caracterizada por la aptitud sensitiva y coordinada por la imaginación, que conecta con los genes mediante la memoria automática, por lo que da cierta seguridad, pues no falla, ni se altera; sólo proporciona deseos. Por último, el tercer tipo -la mediación cognitiva- significa entender y ejecutar lo que el otro ordena. Consiste en la comunicación principiada por el conocimiento. Esta ocurre cuando uno comprende la información recibida, cuando se enjuicia y categorizan los datos antes de optar por un comportamiento u otro, efectuando un juicio moral de conciencia con fundamentación axiológica. Entonces, elige y elabora, por sí mismo, una conducta responsable.

Según lo dicho sobre “educación estricta”, se exige una formación ética. Por consiguiente, con relación a los valores, conciencia, moralidad y libertad, conviene también que introduzcamos aquí el procedimiento y resultado de adoctrinamiento. Este se concibe como un modo de comunicar, intentando influir sobre los demás, con una actitud de desprecio fáctico de la persona, buscando el adoctrinador unos concretos rendimientos externos, usando un mecanismo que impide al receptor descubrir el camino por el que se llega a la verdad, ni que llegue a una moral interiorizada ${ }^{1}$.

Además, en el contexto de la educación, tenemos la postmodernidad globalizante., que está relacionada con la metáfora aldea global ${ }^{2}$. Ésta se describe como una destrucción de las fronteras, la expansión de un proceso de secularización, extensión del consumismo, democratización de las políticas, interrelación entre las culturas y organización de una nueva red económica. Si en la cultura tenemos las tecnologías de la información y la comunicación (TICs) de la telemática y la informática, en lo económico tenemos la hegemonía económica de los del norte, endeudamiento de los del sur, las crisis en centro oriente y todo lo que significa el talante neoliberal, que consiste en dejar que el juego de los mecanismos económicos internacionales opere según la "ley de la mano invisible del mercado"3. En lo político sobresale el modelo del "nuevo orden mundial”. Los operadores más vistosos de este proceso son las multinacionales y corporaciones financieras transnacionales, ambas con una expansión de la producción fuera de los límites del estado en el que se montaron y el continuo ir y venir de capitales, principalmente por medios extraños a lo industrial, como las tecnologías de la información y la comunicación. Estas son algunas características de un sector de la llamada postmodernidad. En este entender, la postmodernidad puede ser vista como repercusión cultural (filosófica) de la globalización, que se traduce en la eliminación de muchísimas pautas y costumbres de las sociedades, y en la aparición de conductas, en ocasiones negativas. 
En este sentido, podemos decir que las conductas no deseables tienen varios orígenes o causas: entre ellas, la violencia del medio (barrio, comunidad) en que viven y se desarrollan cuando niños, la violencia doméstica familiar (psicológica, física, sexual o por negligencia), que sufren desde edades muy tempranas y la exposición a los medios de comunicación masiva, sobre todo la televisión, que les ofrece, como producto de consumo diario, las más variadas formas de violencia psicológica, física, sexual, autoinfligida o contra terceros. Relacionando la televisión y la comunicación, podemos ver la síntesis de todo el malestar de la cultura, que se refleja en las "pantallas de la violencia” (Peiró, 2007), y que agrava la problemática en cuestión.

Teniendo presentes tales premisas, nos formulamos interrogantes del siguiente tipo: ¿Favorece el sistema televisivo esta comunicación iniciada por lo intelectual?, ¿Debe presentar criterios cualitativos, análogamente al sistema escolar, en cuanto a coherencia de programas y explicitación de principios?, ¿'Son conscientes los responsables de los niños, o los espectadores, de la incidencia real de las acciones televisadas sobre la estructuración de su subjetividad del educando? ¿De qué manera influye la televisión en la educación del alumno? ¿La televisión, como forma de entretenimiento, al que los alumnos están expuestos en su tiempo de ocio, influye positiva o negativamente en el alumno? Veamos algunas investigaciones sobre el problema.

\section{La televisión y el ocio: impacto sobre los niños y adolescentes}

Se llama ocio o tiempo libre al que se dedica a actividades que no son ni trabajo, ni tareas domésticas esenciales. Es un tiempo recreativo que se usa a discreción. Es diferente al tiempo dedicado a actividades obligatorias como trabajar, estudiar, hacer tareas, etc. El ocio es tomado por Hegel como una actividad realizada para descansar del trabajo. Debe tener, como toda actividad, un sentido y una identidad. La distinción entre las actividades de ocio y las obligatorias no es estricta y depende de cada persona, así estudiar, cocinar o hacer música puede ser ocio para unos y trabajo para otros, pues estas últimas pueden hacerse por placer además de por su utilidad a largo plazo. Al ocio se lo puede emplear en actividades motivadoras y productivas. Las actividades que cada persona realiza en su tiempo libre pueden constituir aportes o perjuicios, tanto al desarrollo individual, como a la sociedad.

Debido al trabajo, y al estrés que se genera en la sociedad moderna, el ocio es necesario para el individuo. El ocio le ayuda a relajarse de tensiones, propias de sus obligaciones y actividades cotidianas. Las actividades de ocio son directamente proporcionales con el estatus social del individuo, Es decir, una persona que pertenece a una clase social alta no se divierte con las mismas cosas que un joven de clase media, ni con las mismas 
cosas con las que se entretiene un joven de estratos sociales bajos. Tampoco un niño se divierte con las mismas cosas de un joven, ni menos con las de un adulto o de adulto mayor.

En sociedades postindustriales, como la nuestra, el ocio está directamente vinculado con el empleo de recursos tecnológicos, como la televisión. Según muchos investigadores, entre ellos Robinson, los niños y adolescentes emplean más tiempo en ver la televisión que en hacer cualquier otra cosa. Es ilógico pensar que esto afecta en gran medida a su conducta ${ }^{4}$, en muchos casos, negativa. Esto es aseverado por un artículo publicado por la Academia Americana de Psiquiatría de la Niñez y Adolescencia titulado Los niños y la violencia en la televisión ${ }^{5}$. En él se afirma que muchos niños (norteamericanos) pasan un promedio de 3-4 horas diarias viendo televisión. Ante tal aseveración, nos preguntamos cómo tenemos esa ratio en España. La respuesta a esta interrogante la observamos en el siguiente gráfico:

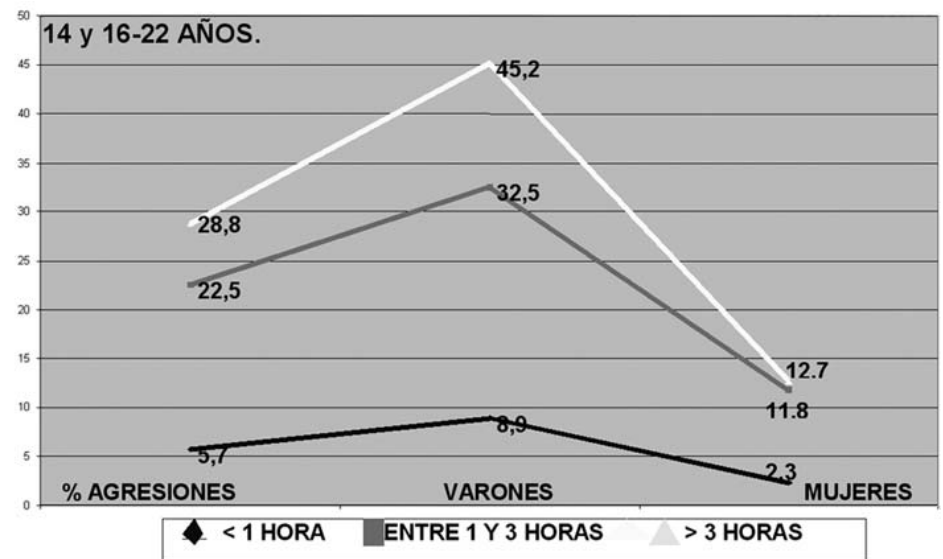

Si el tiempo medio anual por alumno de horario escolar (Las Provincias, 6-1-1991) es de 950 horas anuales, mientras que la exposición ante la televisión es de 1450, el tiempo medio de televisión por alumno es de 211 minutos /día, sumando otros de 35 para vídeo. Pero, más del 50\% de alumnos ven televisión más de 211 min/día. Además, los niños españoles ( $A B C, 12-X I I-1993)$, entre los 3 y 10 años, dedican de 3,30 a 4 horas por día en ver la televisión, cuando un estudio de la Sociedad Europea de Biosociología (1991) considera que el uso razonable de la pequeña pantalla no debe superar los 50 minutos diarios.

¿Cómo podemos interpretar estos datos? Una primera aproximación puede ser ésta: sucede una exposición indiscriminada de los niños de todas las clases sociales y sus efectos son contraproducentes en diversos 
órdenes de la persona. Uno es que el tiempo dedicado a la televisión por los alumnos supera en exceso al de estudio en horas de clase. El segundo es una consecuencia: quienes ven más televisión, su rendimiento es más bajo.

Asimismo, según los análisis efectuados, los espacios de mayor audiencia para los niños son los menos recomendables educativamente. Esto se corrobora al indagar sobre los contenidos. Según el British Film Institute ${ }^{6}$, un $20 \%$ de la programación televisiva del Reino Unido está dedicada a las artes. Esto está bien, en comparación a otros estados de nuestro entorno: Italia, Francia y España, donde suele haber un espacio periódico reducido para analizar y difundir sobre cuestiones de arte o literatura. Muy pocas empresas televisivas tienen en su programación algunos documentales y programas educativos de tipo geográfico, histórico o del reino de la naturaleza. Las cadenas privadas apenas prestan atención alguna a este tipo de emisiones. Por consiguiente, la cuestión siguiente estriba en ver los contenidos predominantes.

Notamos que todavía abundan los programas en franjas de horarios en que los menores tienen fácil acceso. Sobre este aspecto, el citado informe del $A B C$ señalaba lo que la televisión ofrecía en una semana: 670 homicidios, 15 secuestros de menores, 848 peleas, 420 tiroteos, 11 robos, 11 desnudos, 20 emisiones eróticas, 30 torturas, 8 suicidios y 13 intentos de suicidio. Los efectos no son halagüeños. Según el juez de Liverpool, con relación al asesinato del pequeño J. Bulger, la televisión fue la inductora para que Jon Venables y Robert Thompson actuaran violentamente. Y, más concretamente, el modelado se centra en el mito Chucky, protagonista de Muñeco diabólico III. Parece que las emisiones no han cambiado en la actualidad. Aparte del estudio criminológico, en donde la Pedagogía colabora interdisciplinarmente para evacuar el informe ad hoc, otras investigaciones nos confirman empíricamente tal aserto. Así, Hendry y Patrick (1977), al estudiar la frecuencia alta o baja de ver la televisión en escoceses de 15 a 16 años, observó que la televisión incidía en el desajuste y hábitos sexuales de la personalidad, además del comportamiento escolar. Los contenidos en base a violencia, conflictos, los «reality» y las series «de acción» (Diener y Wooly, 1981) acarrean conflictos emocionales. No son ya sólo los Rambo, Terminator, etc., también se da la irresponsabilidad, tanto o más morbosa en el llamado reality show, que es una arrealidad en forma de crónica de pseudosucesos, con el correspondiente halo misterioso, incidiendo y hurgando en lo violento, y sin profundizar para explicar lo patológico del asunto.

Una de las principales conclusiones a que ha llegado la Sección de Pediatría Extrahospitalaria de la Asociación Española de Pediatría, tras un estudio epidemiológico sobre la detección de problemas psicosociales en el consultorio pediátrico, es que existe una fuerte relación entre las horas de televisión visionadas por semana y la prevalencia de problemas psicosociales en los niños ${ }^{7}$. Este estudio, en relación con el número de horas que los más pequeños ven la televisión, descubre un perfil de conducta que reúne síndromes de aislamiento, quejas somáticas, ansio/depre- 
sivo, problemas sociales, trastornos de pensamiento, problemas de atención, conductas delictivas, conductas agresivas, alteraciones del sueño, nerviosismo, aislamiento-asocialidad, sedentarismo, cardiopatología, atrofia la actividad intelectual, deficiencia de la capacidad de discernimiento, fracaso escolar y acostumbramiento en la violencia. La conjugación de tales efectos en la subjetividad lleva a que los teleespectadores, sobre todo los adolescentes, banalicen la violencia ${ }^{8}$. Esto ha sido comprobado de manera cuantitativa mediante el estudio relacional entre el aumento de actitud proagresión y el número de horas de atención a la pequeña pantalla (Johnson et al., 2002).

Los psiquiatras de niños y adolescentes, que han estudiado el problema, han encontrado que los menores pueden imitar la violencia que observan en la televisión; identificarse con ciertos tipos, caracteres, víctimas y perpetradores; tornarse inmunes al horror de la violencia, y gradualmente aceptar la violencia como manera de resolver problemas. La televisión puede ser una influencia muy poderosa en el desarrollo del sistema de valores, en la formación del carácter y en la conducta (Urra et al., 2000). Lamentablemente muchos de los programas de televisión contienen un alto grado de violencia. Los jóvenes pueden afectarse aun cuando en la atmósfera familiar no haya tendencia hacia la violencia. Esto no quiere decir que la violencia que se ve en la televisión sea la única causa de conducta violenta o agresiva, pero no hay duda de que es un factor significativo. Así, tenemos un modelado perniciosamente deseducativo. Dicho modelo consiste en que ven el mundo presentado como un cúmulo de acciones violentas, en las que hasta los "buenos" deben recurrir a ella. En la televisión, la violencia se multiplica por diez: no se habla casi nunca de la labor callada y abnegada de muchas personas que hacen el bien a sus semejantes. Por otra parte, el niño se acostumbra a la brutalidad y la ve como un ingrediente corriente: normal, de nuestra sociedad, cuando no lo es. Muchos contenidos que "enseñan” la violencia son una es cuela de cómo matar, cómo vengarse, cómo extorsionar, incluso en sus detalles más repulsivos.

Contamos también con una investigación experimental. Esta constata que la violencia en la televisión y los videojuegos influye negativamente en los niños. Este estudio compara dos situaciones ${ }^{9}$. Se observó a 225 niños de tercero y cuarto de primaria. La variable dependiente versaba sobre la conveniencia de reducir el uso de la televisión, vídeos y videojuegos. Se presentó a los niños el desafío de estar diez días sin ver televisión y luego verla sólo siete horas a la semana. Se les invitó también a ser más selectivos a la hora de elegir los programas y los juegos. Al principio, la media de exposición a la televisión de los chicos era de 15,5 horas a la semana, además de 5 horas de vídeo y 3 de videojuegos. El tiempo de dedicación a la televisión, a finales de curso, cayó en torno a un 30\%. Los resultados se midieron con cuestionarios en los que se pedía a los niños una estimación sobre la agresividad de sus compañeros al principio y al final del estudio. Los investigadores seleccionaron también aleatoriamente al $60 \%$ de los niños de cada escuela con el fin de realizar una observación directa durante los recreos. 
Las conclusiones de la experiencia fueron claras. Los informes de las dos escuelas, al principio, eran semejantes, pero en el grupo sobre el que se realizó la intervención la agresión bajó un 25\% al final del estudio. La implicación de niños de este grupo en incidentes de conducta verbalmente agresiva durante el recreo fue un $50 \%$ menor que la de los chicos del grupo de control. Tanto chicos como chicas se beneficiaron de la intervención y los estudiantes más agresivos experimentaron la mayor caída en su nivel de combatividad.

De los datos anteriores constatamos que hay una manipulación, no hemos demostrado que diseñada, pero sí conocemos que tiene efectos modificadores de los estados de ánimo de los menores, a la vez que hay modelados a favor de disvalores.

\section{Del ocio al efecto manipulador de la televisión: descripción del proceso}

Un tipo muy frecuente de vivencia del tiempo libre entre nuestros menores y jóvenes es lo que podríamos llamar el “ciberocio". Este concepto englobaría a la televisión, los videojuegos, o las múltiples posibilidades de distracción que ofrece Internet. El niño y el adolescente se exponen gran parte de su tiempo libre a este tipo de actividades. La televisión ha sido definida por muchos autores, como Sue Aran, como una "canción de cuna”. En sociedades como las nuestras, al final de la jornada, hacemos uso de nuestro tiempo de ocio viendo la televisión, que nos sirve como una catarsis.

Creemos que el acceso a los medios de comunicación, como la televisión, no tiene por qué ser negativo si no supone una anulación de las experiencias directas, es decir, que la representación no substituya el contacto directo con la realidad. Cuando la televisión o Internet son la única fuente de conocimiento de la realidad, tienen mucho poder porque el menor elabora la concepción del mundo sólo a partir de ellos, hecho que supone la aceptación pasiva de una mediación sin posibilidad de interacción.

En este sentido, podemos comprender el mecanismo de actuación televisiva con el análisis que efectúa Wason (1976) sobre los medios electrónicos, en especial el medio que consideramos, constatando que tanto los niños como los adultos son influidos en su comportamiento porque creen que las imágenes son reales, por lo que la estructura de su personalidad se resiente al desear lograr metas como la de tales personajes, que son irreales.

Los procedimientos educacionales de este tipo de mitologías se efectúan mediante el proceso de identificación (Laplanche y Pontalis, 1981), en virtud del cual un sujeto asimila un aspecto, una prioridad, o atributo del otro. Así se trasforma total o parcialmente en el modelo que produce. Si a esto se añade la circunstancia de invadir la intimidad familiar, consistente 
en romper las escenas del hogar: amor, oración, conversación, etc., resultan ser palanca para convertir más al sujeto en objeto. La sociedad se convierte en fuente de peligros, imagen de una amenaza constante e indeterminada. De este modo, como en principio, el niño es incapaz de distinguir ficción y realidad, se produce la mezcla confusa. ¿Es la propia experiencia la que enseña, o es lo observado? y, ¿Cómo impacta esto en los niños y adolescentes, en virtud de su egocentrismo?

El procedimiento de inserción en ese mundo ilusorio se basa en los efectos neurofisiológicos de la tecnología televisiva (Heneeus, 1981). La explicación fisiológica de esto es como sigue. El potencial de percepción del hombre es de 10/s y el de emisión de la electrónica de 30/s. Si se intercalan mensajes, lo que creemos ver es un agregado parcial de puntos, que se completa en la mente con los que se encienden a continuación. El mecanismo del cerebro de construir su propia imagen queda en desuso. Se sustituye su sentido: «imaginar es una forma de iluminar los hechos, que capacita al hombre para proponerse nuevas visiones del mundo -nada es mostrenco para el hombre, todo debe recibir de él una interpretación-, que da vida al esfuerzo por profundizar en el conocimiento» (Ibáñez-Martín, 1975: 101). Entonces así se produciría la comunicación “mediada” por el conocimiento, y no "principiada” por éste.

Un verdadero proceso de comunicación consiste en la percepción/ recepción del mensaje, la decodificación, y la posterior valoración del mensaje. Sólo entonces se transforma en un "hecho comunicativo, principiado por el propio conocimiento”. No obstante, lo que ocurre, en la realidad, es que el sujeto se encuentra "conectado" a unos aparatos electrónicos que, a su ritmo, va situando en la mente las imágenes ordenadas por la pantalla. Expuesto a un proceso repetitivo, el pensamiento lógico se va apagando y se hace difícil pensar en cualquier cosa. Al estar mediado, la conversación decae y entra un sopor que va oscureciendo la ilusión por algo. Se inhibe la vigilancia por mantener un estilo de vida y muere la capacidad creativa. Sólo se instruyen (acumulan datos), se forman mal (pseudovalores) y no hay una real promoción de la voluntad.

Desde la perspectiva general, acerca de los dibujos animados, los espacios televisivos para niños se están llenando de programas de dibujos animados violentos. Muchos de estos programas son importados directamente de otra realidad sociocultural, lo cual impacta con la línea axiológica autóctona. Sobre este aspecto, el New York Times (de 28 enero de 1993) indicaba que el estilo de los dibujos animados del llamado anime está influyendo a los dibujantes del país, cuyas nuevas producciones son con frecuencia de una violencia no inferior a la de los originales y con un estilo similar de conducta. Los dibujos animados están dirigidos a jóvenes que han crecido con la violencia de los videojuegos y contienen una buena dosis de acciones crueles.

Análogamente, como en los videojuegos, podemos sintetizar lo procesual-mental con lo formal-estético y la dimensión moral desde la con- 
sideración de los valores. Tales medios tecnológicos enseñan un modelo de valoraciones cerradas. Estas son las que el programador ha diseñado aprovechando los estratos instintivos de la subjetividad humana, pero exacerbándolos y llevándolos hasta el límite de centrar el comportamiento del sujeto en un estado emocional casi permanente. Por consiguiente, como la actividad de conciencia, la deliberación y la relación con el mundo de la cultura se basan en discurrir en lo simbólico, la reflexión y comprensión intelectivas se les escapa a quienes son adictos a la televisión. En esto media otra dimensión: se invierten las categorías estéticas (dar belleza a lo siniestro, tentar a que se apiaden del malhechor...), o éticamente: reducir el sentido de la existencia a la ostentación y al poder mediante el logro del objetivo destruyendo a los demás. En suma, los valores están condicionados y denunciados mediante la elevación de los contravalores de los ganadores, que proyectan disvalores sociales y vicios humanos ${ }^{10}$.

Conforme a las definiciones fundamentales introductorias, se constata una mezcla de procesos manipuladores y de adoctrinamiento. Tales acciones no consiguen el autocontrol de la persona, sino, por el contrario, su alienación. La cuestión estriba en saber si es intencional o simple planificación ciega por la mera búsqueda y captación de clientes comerciales. Pero esto es materia para ser investigada por otras áreas de conocimientos. A nosotros nos preocupa la influencia que tienen las tecnologías de la información y de la comunicación, en especial de la televisión, en la formación del alumno.

\section{¿Cómo influye la televisión en la educación personal?}

Diversas investigaciones observan que la televisión le "roba” tiempo al destinado tradicionalmente para efectuar la socialización, por lo que tanto las destrezas intelectuales, como las de socialidad, no sólo menguan, sino que cualitativamente son pobres; hay desequilibrios -foolish behaviory decrece la formación escolar. Al respecto, Singer y Singer (1983) comprueban efectivamente que la televisión influye negativamente sobre la personalidad en los tres dominios: cognitivo, afectivo y motor, pero que también esto se relaciona con el estilo de vida de la familia. Esto está en convergencia con la tesis de Caplan (1981). Según éste, la televisión no es primera causa de estereotipos, pero los cultiva y los hace aflorar, sin distinciones de sexo.

También se han observado los efectos televisivos en grandes sectores de la población. El encuentro sobre Periodismo y sufrimiento (1993) constata los siguientes rasgos: obsesión por entrometerse en la vida ajena, pasividad, excusa para quedarse en la propia mediocridad, disminución de la comunicación interpersonal, por derivación en padres: negligencia en el trato con los hijos, xenofobia e inseguridad en las calles, o sea: delincuencia, incultura, inestabilidad y nerviosismo. Y así, nos encontramos que se crea una ficción que a la vez sobrecoge, admira y atrae. 
Además, la televisión está siendo juzgada axiológicamente como una fábrica de mentiras (Rico, 1992). También, culturalmente analizada, se constata que empobrece el vocabulario, despierta un afán consumista y acarrea la ley del menor esfuerzo intelectual (hay que pasárselo bien a costa de lo que y de quien sea). De este modo, moralmente se opera el mecanismo de pensar que los valores son para otros - por ejemplo para las ONGsque hacen el bien social. Uno no es consciente ni le cabe que le afecten. Así, cada vez hay mayor anonimato, inconsciencia, anomia y atomía... es una constatada despersonalización. Corolariamente, se comprenden mal los valores del contexto sociocultural del educando. Por ejemplo, la tolerancia se interpreta como excusa para no escuchar. En concordancia con esto, los diálogos públicos, convocados en nombre del plural sentir de la ciudadanía, acaban habitualmente sin cambios perceptibles entre los intervinientes. Es el llamado, “diálogo de sordos”.

Comprendamos que esto es facilitado por la insuficiencia del menor para efectuar plenamente las exigencias cualitativas de la comunicación principiada por el conocimiento. En razón de esta característica de la subjetividad de los estudiantes pequeños, ni efectúa juicios intencionados plenamente, ni vive con entera libertad moral. Y también sabemos que si estas capacidades no se cultivan, el resultado sería un bloqueo de la dinámica personal de "conocer-sintiendo-con-actividad-constructiva", quedándose en etapas paraconscientes, cuasiformales, y con muchos factores definitorios de heteronomía.

Trasladando estas afirmaciones en planteamientos de tipo pedagógico, los efectos se concretan en las siguientes proposiciones: a) el mundo que es percibido como real mediante el receptor de TV, está corregido, editado y vendido, b) es fácil olvidar la propia identidad ante un ordenador u otro medio de las tecnologías de la información (los resultados de una serie de investigaciones han puesto en evidencia que muchos niños no saben efectuar operaciones aritméticas sin calculadora, y se aburren si no manejan un juego virtual, c) de mayores conocerán (y conocemos) muchas noticias, datos, pero en verdad no comprenden casi nada. La razón es que no se hacen juicios de valor, sólo se llega a razonar, sin asimilar la información, que ahoga, atiborra, d) suele confundirse la experiencia sintética con lo real. Por ejemplo, provocar ciertos estados emotivos mediante escenas de spots publicitarios, secuencias de filmes, etc. Así, lo íntimo, que debería estar al margen de la técnica, llega a ser manipulado (pensemos cómo se ha modelado la mente de ciertos sujetos perpetradores de suicidios, homicidios, robos, etc.), por lo que nuestra subjetividad es controlada mediante emisiones de ciertos programas.

La consecuencia se halla en la entredicha noción de adoctrinamiento. Así, tenemos un mundo que es diseñado a espaldas del teleespectador, porque contribuimos a que así sea. En consecuencia, la televisión, como sistema global, está pasando de ser un medio de educación informal -en el sentido de producir efectos aintencionales en la audiencia y de mera diversión- a incidir educativamente de modo no formal. Esto se debe, aparte de 
la intencionalidad, a otros factores, entre los que se encuentran los temporales, configurativos, etc., lo cual les da gran peso con relación a otras instituciones tradicionales.

Finalmente, no debemos despreciar los efectos positivos que tiene la televisión (García, 2003) que resultan menos subrayados y pueden ser más abundantes si son cabalmente planeados. Taylor y Skanes (1977), estudiando niños entre los 5 y 7 años de poblaciones diseminadas y aplicándoles el programa sobre escenas cotidianas en Barrio Sésamo-Sesame street-, constatan ganancias en destrezas prelectoras, de organización cognitiva, solución de problemas y conocimiento de su medio. Sobre estos programas realistas, al examinar el contenido y su mensaje ético, en relación con las realidades familiares (Rabin et al., 1991), se constatan que las percepciones influyentes disminuyen con la edad, pero que tampoco hay grandes diferencias entre lo muy realista y lo algo real. En esta línea (Morrison et al., 1980), los primeros valoran más rígidamente su vida, ciñéndose a los criterios de la televisión, mientras que los mayores aprenden a distinguir lo real de lo ilusorio.

Además, la televisión tiene efectos positivos en el niño, cuando se le ha enseñado a verla, como la facilidad para asimilar el lenguaje, y constituye una excepcional fuente de conocimientos. Por consiguiente, dentro de los estudios de informática del currículo, no estaría de más desarrollar unidades sobre la enseñanza del manejo criterial de los receptores de emisiones de televisión, sobre el debido uso de los videojuegos, aprovechamiento moral de Internet, etc.

\section{Preparando la conclusión}

Los valores plasmados en las TIC no son la consecuencia necesaria y predeterminada de los factores que conforman el entramado formativo básico. Pero no es menos cierto que difícilmente se pueden entender los cambios de valores, así como el auge y el retroceso de determinados universales, éticos en una sociedad concreta, en un momento concreto de la historia, sin relacionar esos valores con los factores estructurales y básicos configuradores de esa misma sociedad.

Con relación a la globalización, entendemos, como Habermas (1989), que es cuestión de crisis axiológica, mas no en el valor por sí, sino en derivación del enfoque dado desde la fundamentación de la modernidad. La razón ilustrada no agota el conjunto de la persona, con un intelecto "sentiente" (Zubiri) o la más empírica "inteligencia emocional” (Goleman). Lo modernista es la aplicación de una lógica pura operante con datos noéticos de la cultura; otro asunto es la razón práctica. Ambos separados desde Descartes, y sistematizados por Kant, en los términos referidos simplificadamente. A la vez, desde el influjo anglosajón, lo emocional va tomando sobrepujanza con relación a lo esencial de lo axiológico. 
No vamos a quedarnos en los aspectos pragmáticos que la globalización ocasiona en el mundo educativo. Entendemos que aquí hay que trascender las meras políticas educativas. Partamos desde la pedagogía axiológica. Si educar es realizar valores en el individuo y en la sociedad, es humanizarlo todo, ¿en qué medida hay respuestas adecuadas a la humanización de este enfoque globalizante?, ¿significará la pérdida del sujeto de la educación en pro de procedimientos y contenidos extraños a su contexto sociocultural?

Para el hombre clásico de siempre, la técnica era como imitación de la naturaleza. El modernista ha tratado de usarla para gobernar las leyes naturales, pero en la actualidad nos pasmamos al ver cómo generamos a partir de ella ${ }^{11}$ otra naturaleza. Por esto, los grupos ecologistas observan con actitud postmodernista la influencia de las tecnologías (TICs) como una bestia que nos ataca. Como consecuencia, por una parte tenemos un medio sofisticado, facilitador, y por la otra, una cultura de la irrealidad (Gónzález Quirós, cap. 5.), como su resultante: “una fe ciega en las TICs, en los canales de transmisión de datos, y a su vez una elevada dosis de conformismo y credulidad”. Es decir, la familia deja al niño en menos de la escuela y las TIC sólo promueven la instrucción. Estas últimas se han convertido en "mediadoras" del conocimiento, con contenidos que adoctrinan y manipulan. Consecuentemente, las posibilidades de efectuar juicios críticos y tomar decisiones responsables se diluyen.

Además, la escuela reducida a instruir sobre contenidos no éticos o, a lo más, mediante una ética mínima, no puede contrarestar la superficialidad que las TIC promueven, en los individuos, mediante procesos de identificación con “modelos, pseudohumanos, modas, etc.”. Por tanto, una inmensa mayoría no tiene la capacidad de comunicarse "principiando" su conocimiento. Entonces, el sujeto no es un verdadero ciudadano; por el contrario, tiende a subyugarse, a actuar como súbdito del candidato de turno.

¿A quién beneficia dejarlo todo a merced de la mano invisible del mercado? Sobre todo si se trata de un medio con tanto potencial configurativo con relación a la capacidad de autodeterminación humana. Si el hombre se forma en y desde la cultura, es un error lamentable "mutarle" mediante un proceso de vaciamiento moral. La suplantación de matrices culturales mitos es tan pérfida que ocasiona una sociedad cansada. Esto se traduce en una realidad sobredeterminada y hacinada por mediadores sociales -instituciones, medios de comunicación social, agencias, etc.- tendentes más bien a producir y reproducir agentes sociales poco responsables, o directamente irresponsables; o bien a generar una sensación general de impotencia, hastío, desánimo y frustración en quienes desearían responder (Argullol y Trías, 1992). Si nos situamos como testigos reflexivos, abstraeremos la esencia de una situación esquizofrénica. La cultura formal iría por un lado, la informal, por otro.

Si Occidente, en general, ha organizado la relación entre unos y otros 
en base al bien común, enjuiciada por juicios racionales objetivos y autocontrol con responsabilización de los propios actos, los efectos mencionados en el razonamiento de los jóvenes y adultos, el afán de consumo, la violencia y otros excesos están potenciando comportamientos inversos a la raíz humanista del modelo sociocultural vigente.

Por tanto, si no se pretende el bien común, si sabemos que tampoco se diseña el mal común -aunque puede acarrearlo-, es que hay intención de un "estar confortable" de unos pocos. Para esto da que pensar que el mencionado control manipulador de la estructura de la persona sea efectivo. En tal suposición, los sujetos se minimizan y se reducen a meros deseos básicos y programables.

\section{Reflexión conclusiva: postura a tomar ante las tecnologías de la información y la comunicación}

Como la televisión forma parte de nuestra vida cotidiana, es un error anatematizarla o prohibir a los jóvenes que la vean, ya que será inevitable que la vean en casa de sus amigos o a escondidas. Lo mejor es acostumbrarles desde muy pequeños a seleccionar, a que disciernan lo que les ayuda o perjudica, y a saber usarla con racionalidad, con mesura y criterio. Hoy día es parte fundamental de la educación y formación integral de los menores, que deberían afrontar la familia y la escuela conjuntamente.

Bien diseñada, la televisión, al igual que los cuentos infantiles, o la novela, cultivan la imaginación, las capacidades valorativas y la relación entre las generaciones mediante la cultura. La razón es que el mito y otras realidades conllevan un componente afectivo que impide una vida anodina. La televisión puede incluir perspectivas en sentido optimizante del espectador.

No hay que caer en la trampa de corregirla sólo con las mismas medidas que aplica: la difusión masiva de mensajes a la contra. Esto generaría una ambivalencia afectiva, con la consecuente paralización -quedarse espectándola, sin más- de la toma de decisiones. Si la comunicación personal se funda en principiarla por lo intelectual, también la comunicación televisiva ha de establecerse con esta premisa. Por tanto, la acción razonada, el diálogo, el respeto a la dignidad, etc. deben incardinarse en los hogares con el fin de que el espectador tome la iniciativa ante las programaciones. Claro, esto conlleva tener una formación de base al respecto. La TV está desprovista de su debida contemplación curricular (Vázquez, 1994); así que enseñar a manejarla, en su sentido instrumental, subrayando más los criterios que las habilidades, es un reto pedagógico.

Otra vía es la tomada por los políticos, que proponen urgentes reformas legislativas, renuncia a parte de los derechos, que reconoce el artículo 20 constitucional. No obstante, hay acuerdos firmados entre Educación y 
Ciencia y las cadenas televisivas, que no se han cumplido. Así, la cuestión parece quedarse entre regular los contenidos desde fuera del sujeto, entre la censura y la libertad de expresión. Esperamos que las nuevas iniciativas impulsadas por la administración española y los directivos de los entes emisores de programas televisivos cuajen en un acuerdo traducido de verdad en hechos y que las palabras y firmas no se las lleve el viento. Pero esto no obvia lo principal: capacitar al sujeto para que sepa deliberar y elegir el programa, así como el tiempo de su consumo.

Es cuestión de jerarquía de valores: ¿Libertad como valor absoluto? Mientras sigue el debate sobre dónde trazar la línea entre la libertad de expresión y la necesidad de salvaguardar a la sociedad, una cosa es cierta: hoy más que nunca los padres necesitan prestar atención a lo que sus hijos ven y oyen. Asimismo, deberían asegurarse de que los valores de la próxima generación no procedan sobre todo de los medios de comunicación de masas, sino que estén formados por la cultura y tradiciones cristianas.

Este aprender a contemplar nos obliga a ver que las medidas externas, entre las que caben las legislativas y administrativas, son insuficientes. Que hay que pasar del heterocontrol al autocontrol, de la heteronomía a la autonomía. Lo de la televisión es pues la punta del iceberg. La televisión puede cumplir su función educativa. Basta que contribuya a promover una comunicación principiada por el conocimiento y así promover valores humanos; es decir, que no sólo sirva para una simple instrucción, sino para una verdadera formación. Este es su deber-ser congruentemente con su paradigma antropológico tendente a la autonomía. Así se arma a los educandos de criterios para transformarla y aprovecharla de manera positiva (Merma, 2008).

¿Cómo llegar a ello? Enseñando los valores como bienes que nutren las asignaturas, al estilo hermenéutico, y con el compromiso con la vida cotidiana. Ir a la realidad es preparar a los sujetos y desde el aula a saber utilizar este instrumento cultural, tan positivo, si se lo maneja con criterio. Para esto hay que contar en el modo de realidad. No nos referimos sólo a sus malos efectos, sino a su utilización.

Después del examen que hemos realizado, constatamos que hay una asignatura pendiente: dar un nuevo impulso a nuestro desarrollo humano y ético. Un objetivo para la educación debería consistir en enseñar a distinguir entre realidad y ficción. En este sentido, partiendo de la importancia de la "escuela paralela", una posible aplicación para investigar la educatividad de la televisión sería elaborar un nuevo modelo educativo integral, que responda a los nuevos retos que nos plantea la sociedad moderna. Para ello, en principio, es necesario tener claros qué queremos lograr con su uso (optimizar el proceso enseñanza-aprendizaje, innovar las prácticas docentes, etc.), y saber qué tipo de funciones (como medio didáctico, medio lúdico, fuente abierta de información) queremos desarrollar. Por supuesto, dicho enfoque debe atender prioritariamente a los primeros estadios evolutivos del individuo. 


\section{Notas}

${ }^{1}$ Reboul, O. (1977), L’endoctrinement. Paris, PUF; Cfr. J. A. Ibáñez-Martín, J. (1983), Adoctrinamiento, Dic. De las Ciencias de la Educación, Madrid, Santillana.

${ }^{2}$ Constructo elaborado en 1964 por McLuhan, M., ver su obra traducida en 1998: Escritos esenciales, Barcelona, Paidós.

${ }^{3}$ Samuelson, P. A. y Nordhaus, W. D. (1986), Economía, Madrid, McGraw-Hills, pp. 458ss y 1115, donde menciona este término usado por Adam Smith sobre la propuesta de política económica del "dejar hacer”.

${ }^{4}$ También debemos mencionar la convergencia de otros medios que operan junto a los receptores de televisión, a saber: 1) Música y dibujos animados. La televisión y los vídeos no son los únicos que promueven la beligerancia. Las letras de muchas canciones modernas son manifiestos sanguinarios. Por ejemplo, una canción del conjunto Slayer festeja los «filos relucientes» y «los ríos de sangre» (The Guardian, 24 enero). 2) Canciones influyentes. Este grupo es ahora objeto de una acción legal por parte de los padres de una chica de quince años, Elyse Pahler; que afirman que fue asesinada en un ritual inspirado por las canciones del grupo musical. Los tres chicos culpables del crimen están en prisión. David y Lisanne Pahler creen que los temas de las canciones de "Slayer" que aluden a asesinatos en serie y necrofilia contribuyeron a la muerte de su hija y han demandado a la banda musical y a la empresa discográfica que distribuye su música. "Este caso no tiene nada que ver con el arte” -declaró David Pahler-. Se refiere a los estudios de mercado. «Slayer» y otros que están en esta industria han desarrollado sofisticadas estrategias para vender música dura a los adolescentes. A ellos no les importa si el mensaje violento y misógino de las letras inspira a los chicos para que hagan daño. Y les importa todavía menos lo que sus fans hicieron a nuestra hija. Lo único que les importa es el dinero”. Los abogados del conjunto y las empresas musicales -incluyendo "Def Jam Music", "Columbia Records", "Sony Music Entertainrnent” y “American Recordings"- declararon que el trabajo de "Slayer" está protegido por el derecho a la libertad do expresión de la Constitución de Estados Unidos. Pero Hollywood y Estados Unidos no son los únicos criticados por la violencia gratuita, incluida en los medios de comunicación. Se acusa a las películas japonesas, e incluso a los dibujos animados, de ofrecer contenidos sanguinarios. Un ejemplo reciente es la película "Battle Royale”, en la que 42 jóvenes son conducidos a una isla remota, y son obligados a jugar la última partida de "Survivor": matar o ser matado hasta que sólo quede uno.

${ }^{5}$ En Internet www.psych.med.umich.edu/web/aacap/. También en Pediatrics Vol. 107 N $^{\circ}$ 2, february 2001, pp. 423-426.

${ }^{6}$ http://www.bfi.org.uk/

7 Álvarez, M. (2003), Folletos Arvo, abril, 2003. La autora es periodista y directora de la revista de la Agrupación de Telespectadores y Radioyentes (ATR).

${ }^{8}$ Una breve explicación de cada aspecto: alteraciones del sueño. Un gran porcentaje de la población infantil pierde horas de sueño a causa de la televisión: se acuestan tarde y se levantan pronto para verlos dibujos animados. Por otra parte, es frecuente que sufran insomnio, pesadillas o trastornos relacionados con lo que han visto, más aún si se trata de violencia. Nerviosismo: ver demasiada televisión produce estrés e irritabilidad. Es también consecuencia de las alteraciones del sueño. Aislamiento: el encerrarse en los programas de 
tele visión conlleva la pérdida de las relaciones familiares o con otros niños. No se juega, no se piensa, no se habla. Sedentarismo: la cantidad de horas que se pasa sentado frente al televisor Le sustrae de jugar o hacer ejercicio. El sedentarismo favorece le obesidad, agravado por la ingestión de chucherías (chocolate, palomitas, etc.) que suele acompañar a la “tele”. Atrofia la actividad intelectual: el niño que ve mucha televisión piensa poco. La gran avalancha de información y de imágenes que le llega en pocos minutos impide la asimilación y la reflexión. Pérdida del discernimiento: en los programas de ficción se desarrolla muy pobremente la realidad. No sólo se situaciones, sino que a menudo es clara mente falsa (por ejemplo, en una pelea el protagonista recibe un sinfín de patadas en el estómago sin que pase gran cosa; en la realidad, una sola patada de ésas le hubiera llevado al hospital). Fantasía y realidad se presentan muy mezcladas y es difícil distinguirlas. Fracaso escolar: todos los expertos coinciden en afirmar que ver mucha televisión produce apatía intelectual, desgana por estudiar o hacer la presenta distorsionada en conceptos y los deberes, pérdida de memoria, etc.

${ }^{9}$ El British Medical Journal de 27 enero menciona los trabajos dirigidos por el doctor Thomas Robinson, profesor ayudante de Pediatría de la Universidad de Stanford, en Palo Alto, California. La investigación se llevó a cabo en centros de San José de California. Las escuelas fueron seleccionadas por estar en el mismo distrito y presentaban características académicas y sociodemográficas análogas. En una de las instituciones no se hizo ningún tipo de intervención sobre 120 niños, servía como grupo de control. En la otra, se impartieron a 105 alumnos 18 lecciones, de entre 30 y 50 minutos, durante seis meses.

${ }^{10}$ Cfr. Vera, María Isabel y Espinosa, Dina (2000), Efectos de los videojuegos y de la realidad virtual en los valores, en Revista Alquibla, 7, Universidad de Alicante, 471-485.

${ }^{11}$ Pensemos lo expresado por Descartes en su Discurso del método: “es posible encontrar una [teoría] práctica, por medio de la cual, conociendo la fuerza y las acciones del fuego, del agua, del aire, de los astros, de los cielos y de todos los demás cuerpos que nos rodean (...) [nos hacemos] como dueños y poseedores de la naturaleza”. 


\section{Bibliografía}

Aguaded, J. I. (1996), Comunicación audiovisual en una enseñanza renovada, Comunicar, Huelva.

Aguaded, J. I. y Cabero, J. (Eds.) (2002), Educar en Red. Internet como recurso para la educación, Aljibe, Málaga.

Aguaded, J. I. y Cabero, J. y Salinas, J. (Eds.) (2003), Diseño, producción y evaluación de medios para la formación, Alianza, Madrid.

Álvarez, M. (2003), Folletos Arvo, abril.

Argullol, R. y Trías, E. (1992), El cansancio de occidente, Destino, Barcelona.

Cabero, J. y otros (2000), Medios audiovisuales y nuevas tecnologías para la formación del siglo XXI, Diego Marín, Murcia.

Ídem (2000), Nuevas tecnologías aplicadas a la educación, Síntesi, Madrid.

Caplan, Jennifer (1981), The relationsheep between Childre's use of television and stereotypes about ocupations and personality attributes, 64 Annual Meeting of the Assocation for Education in Journalism, East Lansing, Michigan.

Choza, J. (1990), La realización del hombre en la cultura, Rialp, Madrid.

Esteve, José Manuel (1983), “El concepto de educación y su red nomológica”, en AA.VV. Teoría de la educación I, Límites, Murcia.

Ferrés, J. (1994), Televisión y educación, Paidós, Barcelona.

García, A. (2003), Una Televisión para la educación: La utopía posible, Gedisa, S.A.

Gónzález Quirós, J. L. (1998), El porvenir de la razón en la era digital, Síntesis, Madrid.

Habermas, J. (1989), El discurso filosófico de la modernidad, Taurus, Madrid.

Heneeus, Pablo (1981), “Efectos mentales de la tecnología televisiva”, Psicodeia. 57, mayo, Centro de Educación Continua de la Universidad Nacional de Australia.

Ibáñez-Martín, José Antonio (1974), “La manipulación y el hombre contemporáneo”, Revista de Estudios Políticos, 195-196, mayo-agosto. 
Ídem (1975), Hacia una formación humanística, Herder, Barcelona.

Johnson, Jeffrey et al. (2002), “Television Viewing and Aggresive Behavior During Edolescence and Adulthood”, Science, 29-III-2002.

Laplanche, J. y Pontalis, J. B. (1981), Diccionario de psicoanálisis, Labor, Barcelona.

Marín-Ibáñez, R. (1976), Valores, objetivos y actitudes en educación, Miñón, Valladolid.

Majó, Joan (2002), “Los profesionales de la comunicación en la sociedad del conocimiento”, Conferencia dictada dentro del IV Congreso Internacional sobre Comunicación, Universidad y Sociedad del Conocimiento, organizado por la Universidad Pontificia de Salamanca, 24-26 de enero de 2002.

Merma, Gladys (2008), “Competencia del Profesorado para el uso de las tecnologías de la información y la comunicación en la enseñanza, en el marco del Espacio Europeo de Educación Superior”, en R. Roig, Investigación e Innovación en el Conocimiento Educativo Actual, pp. 317-326, Marfil, Alicante.

Morrison, Patricia y colab. (1980), "Reasoning about the realities on television: a developmental study”, Technical report $N^{\circ} 18$, Harvard University, Cambdridge, Mass. National Institute of Education, Washington, D.C.

Peiró, Salvador (1994), Pedagogía, ilusión y calidad, Revista de Letras de Deusto, vol. 24, N ${ }^{\circ} 63,31-50$.

Pérez, J. M. y otros (2000), Comunicación y educación en la sociedad de la información, Paidós, Barcelona.

Rabin, B. et al. (1991), Children's perceived realism of family television series, National Institute of Mental Health, Bethesda.

Reboul, O. (1977), L’endoctrinement, PUF, París.

Samuelson, P. y Nordhaus, W. (1986), Economía, McGraw-Hills, pp. 458ss y 1115, Madrid.

Singer, Jerome y Singer, Dorothy (1983), "Psichologists look at television: cognitive, developmental, personality and social policy implications”, American Psychologist, vol. 38, N 7.

Taylor, Lome y Skanes, Graham (1977), The effects of Sesame Street in Isolated communities, Annual Meeting of the American Educational research Association, New York. 
Urra, J.; Clemente, M. y Vidal, M. A. (2000), Televisión: Impacto en la infancia, Siglo Veintiuno de España, Madrid.

Vázquez, Gonzalo (1994), El profesor del futuro y las nuevas tecnologías, en P. Ortega y F. Martínez, Educación y nuevas tecnologías, Cajamurcia, Murcia.

Vera, María Isabel y Espinosa, Dina (2000), “Efectos de los videojuegos y de la realidad virtual en los valores”, en Revista Alquibla, 7, Universidad de Alicante, 471-485.

Wason, Walter (1976), “The future of educational media”, Annual Meeting of the Audiovisual Communications Association of Minnesota Association of School Librarinas, octubre.

Recibido: 26.01.2010

Aceptado: 17.03.2011 